\title{
VERDAD Y JUSTICIA EN AMÉRICA LATINA EN CASOS DE VIOLACIONES A LOS DD.HH.
}

\author{
TRUTH AND JUSTICE IN LATIN AMERICA IN CASES OF VIOLATIONS TO THE \\ HUMAN RIGHTS
}

Héctor Salazar Ardiles*

Fecha de recepción: 6 mayo de 2010.

Fecha de aceptación: 17 de mayo de 2010

\begin{abstract}
Resumen
El presente artículo da cuenta de los procesos de transición de diversas dictaduras militares de Hispanoamérica a regímenes democráticos, ocurridos en las últimas tres décadas del siglo pasado, poniendo el foco de atención en la manera como en distintos países de la región se enfrentó la pesada carga en materia de violaciones a los derechos humanos heredadas de esas dictaduras, así como los diferentes grados de verdad y justicia alcanzados en cada uno de esos procesos, como las di 凶cultades que surgieron para alcanzar dicho cometido. Especial consideración se hace con respecto al caso chileno y los resultados obtenidos en esta área.
\end{abstract}

Palabras clave : impunidad, transiciones, verdad y justicia, deuda, dictaduras, democracia.

\begin{abstract}
The present article gives account of the processes of transition of diverse military dictatorships of Hispanic America to democratic rate happened in the last three decades of last century, putting the area of attention in the way since in different countries of the region the heavy load faced as for violations the human rights inherited from these dictatorships, and the different degrees indeed and justice reached in each of these processes as the dif Dculties that arose to reach the above mentioned assignment. special consideration is done with regard to the chilean case and the results obtained in this area.
\end{abstract}

Key words: impunity, transitions, truth and justice, debt, dictatorships, democracy.

\footnotetext{
* Abogado. Licenciado en Ciencias Jurídicas y Sociales, Universidad Central de Barcelona, España. Profesor de Derecho Político en la Universidad Academia de Humanismo Cristiano y Universidad Católica de Temuco. Profesor invitado de la Maestría en Derechos Humanos de la Universidad Rafael Landivar de Guatemala. Profesor invitado del diplomado de Especialización en Derechos Humanos y Comunicación, impartido por la fundación Henry Dunant América Latina.
} 
Nuestro continente desde 1970 y hasta fines del 90 ha sufrido violentos conflictos sociales y políticos que dejaron tras de sí una pesada herencia en materia de violaciones a los derechos humanos.

Cuando esos conflictos comenzaron a ser superados y nuestras comunidades nacionales buscaron recobrar su normalidad democrática, quizás uno de los problemas más serios que debieron enfrentar decían relación en cómo enfrentar esa herencia de un modo que los caminos decididos permitieran dar un cauce civilizado y éticamente aceptable a fin de superar dichos traumas.

Se trataba de compatibilizar un proceso efectivo y sostenible de normalización democrática con las crecientes necesidades de establecer la verdad y realizar la justicia de cientos de miles de graves crímenes.

Esta inmensa tarea -por cierto- que no resultaba fácil si se tiene presente que nuestras sociedades fueron profundamente afectadas por una violencia política "generalizada" caracterizada por muertes, desapariciones forzadas, torturas, dictaduras militares y guerras internas.

Lo anterior ha llevado a plantearnos cómo reconciliar sociedades profundamente fracturadas, establecer la verdad de todo lo ocurrido y hacer la justicia necesaria con relación a tanto crimen.

Sin duda, hoy hay conciencia general de que esa reconciliación (o reencuentro como señalan otros) no es posible si no hay verdad, ni verdad sin justicia.

Hace treinta años solo tres países de Latinoamérica tenían sistemas democráticos de gobierno. En la actualidad, la situación es inversa, contando nuestros países con sistemas institucionales que garantizan, al menos en el papel, los derechos fundamentales.

En algunos de nuestros países, como forma de reencontrarse con su proceso de democratización, se establecieron comisiones de la verdad y de esclarecimiento histórico, entendidas como instrumentos idóneos para investigar los atroces acontecimientos del pasado reciente y garantizar la justicia.

En algunos casos, dichas instancias fueron creadas como instituciones oficiales, por ejemplo en Chile (Comisión Rettig), Argentina y Perú, o fueron fruto de iniciativas de la sociedad civil y, particularmente, de las ONG de DD.HH.; o resultaron como consecuencia de acuerdos de paz como ocurrió en El Salvador y Guatemala.

Dichas experiencias han generado un debate ya de varios lustros que busca comprender los aspectos más relevantes de estos procesos de reconstrucción democrática. 
Sin embargo, algunas conclusiones ya ha sido posible establecer:

- $\quad$ Se trata de procesos muy complejos y de largo plazo.

- No son procesos importables; no existen modelos o recetas válidos en cualquier tiempo y lugar.

- En ellos juega un papel esencial el establecimiento de la verdad y la realización de la justicia, y

- $\quad$ Finalmente, es necesario ir construyendo en ellos una cultura de respeto y promoción de los DD.HH.

La reconstrucción democrática de nuestras sociedades ha estado marcada por una perspectiva de búsqueda de la verdad y la justicia en materia de violaciones a los derechos humanos cometidas dentro de ellas, entendidas, estas, fundamentalmente, como afectación a los derechos civiles y políticos.

En el mundo de los DD.HH. se sostiene, con mucha vehemencia, que no habrá posibilidades de paz y reconciliación en nuestras sociedades si no se hace justicia y se castigue a los culpables de estos crímenes, lo que importa es una afirmación de la justicia retributiva como prioridad inmediata, sin dejar de afirmar también la necesidad de la justicia compensatoria o reparatoria. Con ello, se argumenta, se reducen los riesgos de la autotutela, se inhiben iniciativas de repetir esas experiencias traumáticas, se dignifica a las víctimas, se individualizan las culpas y se fortalece la legitimidad del proceso democratizador.

Así, la justicia se constituye además en un ritual ético y de renacimiento político que afianza el valor de la democracia y se erige en un formidable muro contra la impunidad.

Es precisamente la necesidad de romper el círculo de la impunidad uno de los desafíos más cruciales de este proceso, en nuestra América es uno de los problemas más complejos que se han debido enfrentar.

Si bien es cierto que los tribunales pasan a ser los instrumentos "por antonomasia" necesarios para establecer la verdad y hacer justicia, nuestra realidad nos enseña que nuestros sistemas judiciales no tienen la capacidad o no se encuentran preparados para juzgar crímenes a gran escala. Tampoco, dado su diseño hecho para establecer las responsabilidades individuales, nos entregan una visión global que permita establecer patrones de conductas colectivas que permitieron la violencia y el terror en términos tan masivos. De allí que haya sido necesario, como complemento, dentro del campo de la justicia retributiva, el establecimiento de órganos jurisdiccionales de carácter internacional.

La experiencia indica que la jurisdicción universal y la instalación de tribunales internacionales, con todas las limitaciones que presentan, hacen un significativo aporte en esta materia, incluso, se transforman en una alternativa viable a los tribuna- 
les nacionales, más aún cuando estos se muestran incapaces de acometer esta gravitante tarea.

Existen experiencias interesantes como la del Tribunal de Estraburgo y la Corte Interamericana de Derechos Humanos, que son instancias internacionales de apelación por violaciones a los derechos humanos cuando se agotan los recursos internos del país.

Los mecanismos de la justicia internacional son útiles cuando no se logra la justicia en el propio país; son la respuesta al desarrollo de niveles más altos de conciencia universal respecto de la necesidad de respetar los DD.HH. Asimismo, juegan un rol disuasivo relevante respecto de futuras eventuales violaciones. Además, mediante dichas instancias, la comunidad internacional se involucra directamente en procesos que tienen un fuerte impacto en las comunidades nacionales, haciendo más solidaria y amplia la demanda no satisfecha.

\section{La experiencia de nuestra región}

Tras décadas de vivir bajo el influjo de dictaduras militares y conflictos armados internos, nuestra América Latina se orientó en la década de los 90 hacia la reconstrucción democrática y dio pasos a procesos de reconciliación o reencuentro nacional.

El objetivo de la reconciliación nacional, sobre la base de garantizar una cierta estabilidad del proceso democrático y la refundación o democratización de las instituciones, junto con la definición de una política para enfrentar la deuda pendiente en materia de violaciones a los derechos humanos, fueron los desafíos claves de ese período.

En lo que respecta a la justicia, estos procesos de transición debieron enfrentarse a legislaciones heredadas que buscaban impedir las investigaciones en casos de violaciones a los DD.HH., así como a la autolimitación que se impusieron para evitar conflictos con un poder militar aún vigentes.

En diferentes momentos de las dictaduras o conflictos armados, las autoridades de la época dictaron leyes de amnistía para impedir que se investigaran tales violaciones. Estas leyes fueron un serio obstáculo de las transiciones en la lucha contra la impunidad. Así, por ejemplo, en Chile se dictó el Decreto Ley 2.191. El año 1978, que importó un blanqueo feroz de todos los crímenes de la dictadura. Con todo, no fue el único obstáculo que enfrentaron las acciones judiciales de las víctimas, también se utilizó la institución de la prescripción a fin de eludir investigar casos de torturas, ejecuciones extrajudiciales y desapariciones, y se ejercieron presiones directas desde las FF.AA. sobre las autoridades civiles para frenar el avance de los procesos. Sin embargo, las necesidades de brindar una justicia material fueron presionando a los jueces 
que, superando sus iniciales temores, se abrieron a la tarea de investigar. Un fuerte impulso en este sentido lo brindó la Mesa de Diálogo el año 2000, cuando las FF.AA. terminaron reconociendo que durante la dictadura militar se habían violado los DD.HH. Fue así que se estableció un mecanismo judicial con jueces con dedicación exclusiva a investigar estas causas, y los uniformados se comprometieron a colaborar con la justicia. Antes, las investigaciones judiciales no habían logrado significativos avances, no obstante contar con antecedentes que permitían hacerlo.

En El Salvador, cinco días después de publicación del informe de la Comisión de la Verdad, la mayoría derechista del partido ARENA aprobó en el congreso una amplia amnistía tanto respecto de la responsabilidad penal como civil de los violadores a los DD.HH. Así las víctimas se vieron privadas de accionar a fin de hacer efectiva dichas responsabilidades y reclamar reparaciones respecto de hechos anteriores al año 1992. La Corte Suprema salvadoreña se negó a revisar esa ley.

Por su parte, en Guatemala, con la suscripción de los acuerdos de Paz, la guerriIla y el gobierno convinieron en la reintegración de los ex combatientes, lo que se tradujo en la dictación de la Ley de Reconciliación Nacional, conforme a la cual fueron amnistiados todos los que habían cometido delitos en el marco del conflicto armado, excluyendo la desaparición forzada, la tortura y el genocidio. Jurisprudencialmente, la Corte Suprema guatemalteca ha señalado que el análisis de si es aplicable o no esa amnistía debe hacerse cuando los fiscales conocen del caso, mediante consulta a las instancias jurisdiccionales superiores. Lo anterior, ha inhibido las investigaciones judiciales ya que la Corte Suprema de ese país ha anulado investigaciones en que se había logrado demostrar la responsabilidad criminal de militares, argumentando que no se había realizado ese trámite de la consulta.

En Perú, la justicia ha operado de forma muy desigual. Por una parte, se ha mostrado muy estricta y rigurosa en contra de la insurgencia -Sendero Luminoso y MRTA-, sobre todo durante el gobierno de Fujimori, época en que se Ilevaron a cabo miles de detenciones arbitrarias y juicios sumarios sin ninguna garantía procesal, en tanto que los militares implicados en violaciones a los DD.HH. no fueron investigados. El Congreso peruano decretó una amnistía el año 1995, declarando que "todos los hechos originados o derivados como consecuencia de la lucha contra el terrorismo" cometidos por personal militar quedaban amnistiados. Un mes después, a fin de dejar todo bien amarrado, se aprobó una nueva ley que impedía a los jueces revisar si la amnistía era aplicable o no. Con todo, algunos avances se han logrado recientemente con ocasión del juzgamiento al ex presidente Fujimori, cuando algunos capítulos, materia de la acusación, se refirieron a casos de violaciones a los DD.HH. junto con cargos por corrupción, materia sobre la que también pesaron cargos judiciales, en Chile, en contra del general Pinochet.

El caso argentino también sufrió los embates de la impunidad. A fines de 1983, con el retorno de la democracia a la Argentina, los familiares de la víctimas de la 
represión militar iniciaron la búsqueda de la verdad respecto a la suerte de miles de desaparecidos sufriendo amenazas y marcados por el temor que habían logrado instalar los represores. De allí en adelante la política argentina ha estado marcada por avances y retrocesos en el comportamiento del Estado para dar respuesta a los reclamos por violaciones a los DD.HH. El gobierno de Raúl Alfonsín creó la CONADEP (Comisión Nacional sobre Desaparición de Personas), la que, luego de un año de trabajo, evacuó su informe titulado "Nunca Más", que entregó los elementos necesarios para enjuiciar posteriormente a los autores de los crímenes cometidos durante el período dictatorial. Al efecto se dictó una ley (Ley 23.049) que entregó a la jurisdicción militar dicha tarea. Sin embargo, en 1984, el Consejo Supremo de las Fuerzas Armadas resolvió que las órdenes dictadas en el "ejercicio de la lucha contra la subversión" eran "inobjetablemente legítimas", por lo que las investigaciones en dicha sede no avanzaron. En abril de 1985 la Cámara Federal en lo Criminal y Correccional de la Capital Federal tomó a su cargo estos procesos y dio inicio a los juicios a las tres juntas militares que habían gobernado Argentina. El 9 de diciembre dicho tribunal dictó sentencia sosteniendo la existencia de un plan sistemático, deliberado y concertado para la política de la represión encubierta y condenó a cinco de los comandantes por delitos de homicidios, privación ilegítima de libertad y torturas, entre otros, abriendo cauce a nuevos y numerosos procesamientos en los tribunales del país. Tres años después, esto es en 1987, bajo el eufemismo de que el país no podía vivir en un "estado general de sospecha e incertidumbre", y bajo el pretexto que había que "acelerar los juicios", se dieron los primeros pasos en un proceso destinado a establecer la impunidad en materia de violación a los DD.HH., dictándose las leyes de Punto Final y de Obediencia Debida, por el Congreso durante el gobierno de Raúl Alfonsín. Posteriormente, a tres meses de asumido el mando por el presidente Menem, este dispuso indultar a 267 personas que no se habían beneficiado de las dos leyes dictadas durante el gobierno de Alfonsín. Se trató de 39 militares acusados de graves violaciones a los DD.HH., 64 ex guerrilleros o militantes políticos contrarios a la dictadura militar y tres ex comandantes en jefe de las FF.AA., entre otros.

Por su parte, en Uruguay, una ley que impidió toda investigación en materia de violaciones a los DD. HH, ha logrado imponerse hasta el presente y los intentos de derogarla mediante plebiscitos han fracasado, encontrándose una cerrada oposición de parte de los gobiernos posteriores a la dictadura militar por promover una política de verdad y justicia en estos ámbitos, imponiéndose la impunidad prácticamente sin contrapesos, no obstante la decidida lucha que han dado los organismos de derechos humanos de ese país por romper ese bloqueo.

Brasil ha sostenido persistentemente una política de dar vuelta la hoja respecto de las violaciones a los derechos humanos cometidas durante la dictadura que vivió ese país hace más de tres décadas. No se conocen políticas en materia de verdad y justicia que se hayan promovido desde los gobiernos democráticos postgobierno autoritario. Así las cosas, el cuadro que presenta nuestra región no es muy alentador en estas materias. 
Al parecer, las necesidades políticas de asentar débiles procesos de reconstrucción democrática, se hizo sobre bases muy precarias y bajo la presencia siempre amenazante de los poderes militares cuyo retiro del primer plano de la política y del ejercicio del gobierno de sus respectivos países fue más aparente que real. El poder militar conservó importantes cuotas de poder efectivo que ahora se manifestaba por medio de una suerte de facultad de veto encubierto que se ejerce a través de sus aliados civiles, que históricamente se han encontrado en los sectores más conservadores de la sociedad.

Con todo, a pesar de las dificultades anotadas, las necesidades de verdad y justicia en nuestro continente no han podido ser apagadas. Ha pasado el tiempo y la demanda sigue vigente.

Existe en la conciencia moral de nuestros pueblos de que ello no puede ser soslayado y que tarde o temprano esta deuda pendiente debe ser saldada. Quizás si el caso de nuestro país sea sugerente en este sentido.

Las complejidades de nuestra transición se manifestaron de forma evidente cuando las demandas de verdad y justicia lograban algunos avances. Fue así como la presión militar se hizo sentir en más de alguna ocasión logrando sus objetivos y paralizando a la clase política gobernante muy permeable a dichas presiones.

Así se logró que el tema de la deuda pendiente en materia de violaciones a los DD.HH. fuera desapareciendo de la agenda nacional. Sin embargo, los familiares de las víctimas, asistidas por organismos de DD.HH., no cesaron de requerir de los tribunales de justicia una respuesta. Por cierto que la respuestas era exiguas y los avances muy precarios. Y así pasaban los años.

Las FF.AA. en nuestro país habían apostado a que el transcurso del tiempo iría desgastando estas demanda hasta que dejarían de ser un escollo en el devenir nacional y un problema de pequeños grupos sin mayor significación, así la impunidad se impondría como algo natural: el olvido.

Sin embargo, ocurrió algo no previsto: el año 1999 Pinochet cae detenido en Londres, por acción de la justicia internacional, y el país se ve sacudido por ese hecho. De un día para otro, un tema que había desaparecido del debate aflora potente e intensamente en la agenda nacional, quedando en evidencia que existía un problema pendiente del cual la sociedad no se había hecho cargo: las violaciones a los DD.HH. durante la dictadura militar.

La irrupción del tema y la movilización de la población detrás de él con la consecuente demanda de verdad y justicia llevó a que las FF.AA. de nuestro país, junto con las autoridades de gobierno, emprendieran una iniciativa que se denominó La Mesa de Diálogo de Derechos Humanos, donde, bajo los auspicios del ministro de 
Defensa, se reunieran representantes de los comandantes en jefe de todas las ramas de la defensa nacional con personeros provenientes del movimiento de los DD.HH. y autoridades morales representativas de los sectores más relevantes del país.

Fruto de dicha Mesa de Diálogo, las FF.AA. aceptaron, por primera vez, reconocer que efectivamente durante el gobierno militar se habían violado los DD.HH. y que ello había sido una política sistemática. Se comprometieron a un "nunca más" y a respetar la institucionalidad democrática, reconociendo que la única instancia válida para acometer este problema eran los tribunales de justicia, a los cuales comprometieron toda su colaboración.

Además, se propuso un sistema de jueces con dedicación exclusiva en la tramitación de estas causas, brindándoseles los apoyos logísticos necesarios para llevar a cabo su tarea.

Por cierto que la colaboración ofrecida por las FF.AA. fue más nominal que real, pero la verdad es que la investigaciones judiciales adquirieron un dinamismo impresionante a partir del año 2000, que se traduce en la siguiente estadística de resultados:

\section{Causas por violaciones a los DD.HH. al 31.7.2010}

1) Total de juicios: $\mathbf{4 2 3}$

2) Estos 423 juicios involucran a $\mathbf{1 . 1 7 1}$ víctimas.

3) Entre el 31.7.2005 al 31.7.2010 han concluido 82 juicios con condenas.

4) Los 82 juicios concluidos con condena involucran a189 víctimas.

5) Desde que hay actividad jurisdiccional por denuncia de violaciones a los DD.HH., se han dictado 3.052 resoluciones de procesamiento o acusaciones que han afectado a $\mathbf{5 5 8}$ agentes del estado (234 de ellos figuran en más de una resolución).

6) Hasta la fecha se han dictado $\mathbf{5 0 6}$ sentencias condenatorias que afectan a $\mathbf{2 9 0}$ agentes del estado, 83 de los cuales tienen más de una condena.

7) Igualmente, hasta la fecha se han dictado 46 sentencias absolutorias a favor de agentes del estado, todas las que se encuentran en fase de apelación.

8) Tipos de agentes del Estado procesados o condenados:

a) 354 miembros del Ejército, 118 ya condenados:

- 32 generales

- 24 brigadieres

- 55 coroneles 
- $\mathbf{2 0}$ tenientes coroneles

- $\mathbf{2 5}$ mayores

- 8 capitanes

- 130 suboficiales

- 39 empleados civiles

- 21 inclasificables

b) $\mathbf{6 0}$ miembros de la Marina, $\mathbf{1 6}$ ya condenados:

- 6 vice o contraalmirantes

- 7 capitanes de navío

- 6 capitanes de fragata

- 30 suboficiales

- $\quad 2$ empleados civiles

- 9 inclasificables

c) $\mathbf{5 2}$ miembros de la Fuerza Aérea, 19 ya condenados:

- 3 generales

- 9 coroneles

- $\mathbf{3}$ tenientes coroneles

- 1 mayor

- 3 capitanes

- 20 suboficiales

- 12 empleados civiles

- 1 inclasificable

- 248 miembros de Carabineros de Chile, 121 ya condenados:

- 6 generales

- $\mathbf{1 7}$ coroneles

- $\mathbf{1 0}$ tenientes coroneles

- 12 mayores

- 10 capitanes

- 178 suboficiales

- 1 empleado civil

- 14 inclasificables

e) 20 miembros de la Policía de Investigaciones, 9 ya condenados.

f) 1 miembro de Gendarmería de Chile, ya condenado.

g) 53 civiles, 6 ya condenados.

9) En total, hasta el presente, $\mathbf{7 8 8}$ agentes del Estado han sido requeridos por nuestros tribunales de justicia por su presunta participación en violaciones a los derechos humanos, de los cuales $\mathbf{2 9 0}$ se encuentran condenados.

En suma, la experiencia indica que la verdad y la justicia son posibles en un porcentaje significativo; que se trata de una demanda que está instalada en la conciencia moral de nuestros pueblos y que más temprano que tarde se abrirán también las anchas alamedas para que esa verdad y esa justicia, aún pendientes, se hagan realidad. 